\title{
Changes in salivary proteome before and after cigarette smoking in smokers compared to sham smoking in non- smokers: A pilot study
}

\author{
Indu Sinha', Jennifer Modesto², Nicolle M. Krebs², Anne E. Stanley³, Vonn A. Walter ${ }^{2}$, John P. Richie Jr.', Joshua E. \\ Muscat ${ }^{2}$, Raghu Sinha ${ }^{7}$
}

\begin{abstract}
INTRODUCTION Smoking is the leading cause of preventable disease. Although smoking results in an acute effect of relaxation and positive mood through dopamine release, smoking is thought to increase stress symptoms such as heart rate and blood pressure from nicotine-induced effects on the HPA axis and increased cortisol. Despite the importance in understanding the mechanisms in smoking maintenance, little is known about the overall protein and physiological response to smoking. There may be multiple functions involved that if identified might help in improving methods for behavioral and pharmacological interventions. Therefore, our goal for this pilot study was to identify proteins in the saliva that change in response to an acute smoking event versus acute sham smoking event in smokers and non-smokers, respectively.

METHODS We employed the iTRAQ technique followed by Mass Spectrometry to identify differentially expressed proteins in saliva of smokers and non-smokers after smoking cigarettes and sham smoking, respectively. We also validated some of the salivary proteins by ELISA or western blotting. In addition, salivary cortisol and salivary amylase (sAA) activity were measured.

RESULTS In all, 484 salivary proteins were identified. Several proteins were elevated as well as decreased in smokers compared to non-smokers. Among these were proteins associated with stress response including fibrinogen alpha, cystatin A and sAA. Our investigation also highlights methodological considerations in study design, sampling and iTRAQ analysis.

CONCLUSIONS We suggest further investigation of other differentially expressed proteins in this study including ACBP, A2ML1, APOA4, BPIB1, BPIA2, CAH1, CAH6, GYTA, DSG1, EST1, GRP78, GSTO1, sAA, SAP, STAT, TCO1, and TGM3 that might assist in improving methods for behavioral and pharmacological interventions for smokers.
\end{abstract}

\author{
AFFILIATION \\ 1 Department of Biochemistry \\ and Molecular Biology, \\ Penn State Cancer Institute, \\ Hershey, United States \\ 2 Department of Public \\ Health Sciences, Penn State \\ Cancer Institute, Hershey, \\ United States \\ 3 Mass Spectrometry and \\ Proteomics Core, Penn \\ State University College of \\ Medicine, Hershey, United \\ States \\ CORRESPONDENCE TO \\ Raghu Sinha. Department of \\ Biochemistry and Molecular \\ Biology, Penn State \\ Cancer Institute, 500 \\ University Drive, Rm. T4415, \\ CH76 Hershey, PA 17033, \\ United States. E-mail: \\ rus15@psu.edu

\section{KEYWORDS} \\ proteomics, saliva, salivary \\ alpha amylase, smokers, non- \\ smokers
}

Received: 8 March 2021 Revised: 31 May 2021 Accepted: 31 May 2021

\section{INTRODUCTION}

Smoking is the leading cause of premature mortality ${ }^{1}$. A major reason smokers have a difficult time quitting is the need to alleviate psychological stress and negative mood. Clinically, this is known as selfmedication, where smoking is used to lower negative mood and stress, and increase positive mood. The behavioral reactions are rapid, as nicotine reaches the brain in a number of seconds. A single cigarette, which typically is only puffed about 10 times, is sufficient to temporarily satisfy smoking cravings and increase positive mood. Preclinical research also shows that stress increases drug self-administration and drug seeking behaviors. Some antidepressants facilitate 
smoking cessation but the mechanism is not known ${ }^{2}$. Little is known about the biology, psychology and the interplay between psychological and biological stress in response to smoking. There is a stress indication model of smoking, which postulates that soon after finishing a cigarette, smokers begin to experience adverse psychological symptoms such as changes in mood and stress associated with acute nicotine withdrawal ${ }^{3}$. The stress hormone cortisol is the standard biomarker of stress response, representing the activation of the hypothalamic-pituitary-adrenal (HPA) axis pathway. Both salivary amylase protein levels and sAA activity have also been used in stress research. Smoking related literature indicates impact on sAA activity as one of the stress related markers $^{4,5}$. Given the limited effectiveness of standard of care treatment for nicotine dependence (e.g. counseling and nicotine pharmacotherapy), a greater understanding of the role of stress could potentially lead to new and improved methods for behavioral and pharmacological interventions.

The typical pack-a-day smoker waits approximately 60 minutes or less between each cigarette throughout awake-hours. The maintenance of smoking throughout the day is thought to reflect smokers' attempts to regulate mood and feelings of relaxation.

The biological pathways in the maintenance of smoking from one cigarette to the next are not well understood. The one established mechanism is that smoking increases adrenocorticotropic hormone (ACTH), which stimulates cortisol secretion ${ }^{6,7}$. This response has been attributed to the nicotine in tobacco smoke $^{8}$. In the drug dependence field, proteomics has been proposed to identify protein patterns that underlie psychological and neurological mechanisms ${ }^{9}$. A study demonstrated rapid effects of stress-induced HPA activation in rats, following only a 15-minute physical stressor ${ }^{10}$. Hwang and $\mathrm{Li}^{11}$ identified several differentially expressed proteins in various brain regions of rats administered with nicotine. Cecconi et al. ${ }^{12}$ observed significant changes in C-reactive protein along with other serum proteins in rats at different time points during nicotine administration and nicotine extinction cycles within a 2 -week period. Rat models have also been recently employed to study secondhand smoke exposure ${ }^{13}$.

There are mixed findings on smoking status and cortisol. The Steptoe et al. ${ }^{14}$ study found smoking is associated with an acute increase in cortisol, and 6-week abstinence reduced cortisol. Although it has been reported for decades that smoking helps reduce negative affect, the effect is temporary whereas smoking increases the heart rate, which increases anxiety, a physiological component of the stress response ${ }^{15}$. One study showed that long-term quitters had reduced perceived stress levels compared to non-quitters ${ }^{16}$. The application of proteomics to understanding nicotine dependence is virtually unexplored. Nicotine dependence is thought to be due to the moods (e.g. relief of stress, anxiety, etc.) associated with nicotine intake ${ }^{6}$. While a number of studies have investigated the effects of nicotine on a specific gene or protein response, in either in vivo or in vitro systems ${ }^{9}$, systematic studies on proteomic profiles during chronic exposure to nicotine have not been conducted and few studies on nicotine consumption in free living smokers have been reported. Moreover, sAA exhibits a stable circadian pattern that mirrors that of salivary cortisol, and has the potential to be accepted as a non-invasive biomarker for the sympathetic nervous system (SNS) ${ }^{17,18}$. However, there are few data on how it is influenced by smoking.

Several biological fluids have been used for measurement of proteins in smokers including plasma $^{19}$, sputum ${ }^{20,21}$, bronchoalveolar lavage fluid ${ }^{22,23}$, and saliva ${ }^{24,25}$. We have also used exhaled breath condensate (EBC) for lung proteomics ${ }^{26}$ but EBC and BALF are methods suited for studying proteins in the respiratory tract. In addition, cortisol is a key marker for the purposes of this study, which can be obtained from saliva but not EBC. Saliva is also considered an easily obtainable clear fluid, which is indicative of individual's profile at the time of collection. For research subjects, the non-invasive collection techniques of saliva dramatically reduce the anxiety and discomfort and simplify procurement of repeated samples for monitoring overtime.

The goal of the current pilot study was to determine the feasibility of using proteomics in human subjects' research to identify new protein markers in response to acute smoking. There is a model for studying the acute effects of cigarette smoke on biological responses in vitro ${ }^{27}$ and in humans ${ }^{28}$. We took a similar approach for the current pilot study and analyzed saliva samples from current smokers and non-smokers before and after smoking two cigarettes/ 
sham smoking two cigarettes, respectively, with a gap of $60 \mathrm{~min}$ between smoking sessions, using isobaric tags for relative and absolute quantitation (iTRAQ) methodology to identify new proteins that might assist in understanding changes that occur in the stress response to smoking.

\section{METHODS}

\section{Participants}

Smokers included three males and two females (aged 19-55 years) that had previously participated in the Pennsylvania Adult Smoking Study ${ }^{29}$. Inclusion criteria for this pilot study were: smokers, aged $\geq 18$ years and smoked at least 1 cigarette (Cig) per day for the past year; non-smokers, aged $\geq 18$ years and not smoked in the past 2 years. Exclusion criterion was: being pregnant. All smokers were Caucasian with less than college education and participants smoked between 15-30 cigarettes per day. Four control samples were obtained from non-smoking employees aged 19-55 years including two men and two women. All were college educated. Three were Caucasian and one was Asian. All the participants signed a consent form prior to their participation in the pilot study. The study was conducted in accordance with the Declaration of Helsinki, and the protocol was approved by the Institutional Review Board (IRB\# PRAMS042265EP) of Penn State University College of Medicine.

\section{Procedures}

All participants entered the study by completing a telephone interview that determined eligibility and were provided a description of the study. Participants who were eligible and interested were scheduled for one study visit at home for smokers. For nonsmoker participants the visit was hosted within the laboratory setting of Penn State College of Medicine. At the visit, participants gave written consent and completed interviewer-administered questionnaires. The smokers were asked to smoke their usual brand of cigarette and after a mouthwash they were asked to chew on flavor-free gum; $6-8 \mathrm{~mL}$ of saliva was collected, by spitting, into a glass Pasteur pipette in a DNAse-RNAse-free polypropylene tube containing $1 \mathrm{mM}$ sodium orthovanadate and protease inhibitors (Sigma-Aldrich, St. Louis, MO) and placed on ice. The smoking session was repeated after a gap of at least $1 \mathrm{~h}$ and tubes from both collection times were stored on ice for 1-2 $\mathrm{h}$ at which point, tubes were transported to the laboratory for further processing. Non-smokers were asked to use a sham unlit cigarette and perform the saliva collection as described above. Saliva samples were collected from 5 smokers and 4 non-smokers before and 30 minutes after each smoking session. Saliva tubes were centrifuged at $10000 \mathrm{rpm}$ for $10 \mathrm{~min}$ at $4^{\circ} \mathrm{C}$ and separate aliquots of supernatants were stored frozen at $-80^{\circ} \mathrm{C}$ until analysis. Most studies of changes in reported stress level have looked at the effects of withdrawal over a long time period. We chose to go with an acute time frame of $30 \mathrm{~min}$ after smoking. All studies started at about 12:00-12:30 p.m., to account for the diurnal variation in cortisol levels, which spike in the early morning hours.

\section{Sample processing for iTRAQ analysis}

For the iTRAQ analysis (Supplementary file Figure S1), 5 saliva samples were pooled from smokers separately at baseline and after smoking the first cigarette (Cig 1). Similarly, saliva samples before and after smoking the second cigarette (Cig 2) were also pooled separately. In addition, 4 saliva samples were pooled from non-smokers before and after first sham unlit cigarette smoking separately and before and after second sham cigarette separately for a total of 8-pooled samples. All the samples were processed according to the Penn State University College of Medicine (PSUCOM), Mass Spectrometry and Proteomics Core Facility protocol adapted from the manufacturer's instructions (AB SCIEX, Framingham, MA) (http:// med.psu.edu/web/core/proteinsmassspectometry/ protocols/itraq) as described earlier ${ }^{30}$. Briefly, the iTRAQ methodology involved digesting equal amounts of protein from the pooled samples (100 $\mu \mathrm{g})$ with trypsin and subsequently labeling each pooled sample with a different tag (Supplementary file Figure S1). The 8 different isobaric tags add the same mass to primary amine groups in the tryptic peptides from each pooled sample, but with each tag composed of different proportions of $12 \mathrm{C} \rightarrow 13 \mathrm{C}$ and $14 \mathrm{~N} \rightarrow 15 \mathrm{~N}$ substitutions in one portion of the tag, yielding quantitative fragments ranging from 113 to 121 Daltons upon MS/MS fragmentation. The amount of each of these fragments arising from fragmentation of each peptide peak shows proportionally how much of each peptide peak came from each individually 
labeled sample. The labeling with tags was performed using the iTRAQ ${ }^{\circledR}$ Reagent-8Plex Multiplex kit (AB SCIEX, Framingham, MA). These tagged samples were submitted to the Proteomic Core Facility at PSUCOM. The labeled peptides were then resolved by two-dimensional liquid chromatography prior to matrix-assisted laser desorption and ionization time-of-flight tandem mass spectrometry. The details on the separation and analysis of proteins by 2D-LC as well as the methodology involving mass spectroscopy (MALDI TOF/TOF) are described in the Supplementary file. Peptide identification, protein grouping, and subsequent protein quantitation were done using the Paragon and ProGroup Algorithms in the ProteinPilot ${ }^{\mathrm{TM}} 4.5$ Software package (AB SCIEX, Framingham, MA), searching the NCBI human database plus a list of 389 common contaminants (Supplementary file). The datasets presented in this software are ratios of the condition (e.g. after/before smoking a sham or real cigarette). The p-values were calculated from a standard Student's t-test value, calculated as the average of the logs of the ratios of the individual peptides belonging to each protein divided by the standard error of the average of $\operatorname{logs}$ of the ratios of those peptides. Because of the large number of proteins considered in this experiment, p-values from the ProteinPilot analysis were adjusted to correct for multiple testing. In brief, for each of the four comparisons - 114:113, 116:115, 118:117, 121:119 - the Benjamini-Hochberg procedure was applied to convert the $\mathrm{p}$-values to false discovery rate q-values using the p.adjust() function in R 3.6.3 ${ }^{31}$.

We looked for an effect of smoking by comparing the after/before protein ratios for smokers and nonsmokers. Ratios significantly greater than 1 indicate a differential increase in a given protein after sham or cigarette smoking and ratios significantly lower than 1 indicate a differential decrease in a given protein after sham or cigarette smoking.

In addition to discovered proteins, we measured the following markers of stress.

\section{Salivary alpha amylase (sAA) protein expression by western blot}

Equal amounts of $(10 \mu \mathrm{g})$ saliva proteins were separated on $10 \%$ SDS-PAGE gels and transferred on polyvinylidene fluoride membrane. Anti-salivary alpha amylase and $\beta$-actin (Santa Cruz Biotechnology,
Dallas, TX) antibodies were reacted with the blots at 1:1000 at $4^{\circ} \mathrm{C}$. Following washings in TBS-Tween, horseradish peroxidase (HRP)-conjugated anti-goat secondary antibody was used at a dilution of 1:3000. Band expressions were developed using Pierce ${ }^{\mathrm{TM}}$ ECL reagents (Thermo Scientific, Rockford, IL) and band densities were quantified using Image $\mathrm{J}$ analysis (National Institute of Health, Bethesda, MD). Fold change in band densities of sAA protein were normalized to band density of $\beta$-actin for all the samples.

\section{Salivary cortisol levels}

Salivary cortisol, yet another established stress related marker ${ }^{32,33}$ was measured in saliva samples by commercially available ELISA kit (Salimetrics, State College, PA).

\section{Enzyme activity for sAA}

The sAA activity was measured in duplicate in all the saliva samples from smokers and non-smokers following the instructions provided with Salimetrics Kit (Salimetrics, State College, PA).

\section{Salivary fibrinogen alpha and cystatin A levels}

Salivary fibrinogen alpha and cystatin A were measured by commercial ELISA kits manufactured by Nova Lifetech Limited (Mongkok Ki, Hong Kong) and Assaypro LLC (St Charles, MO), respectively.

\section{Statistical analysis and power}

Quantitative levels of fibrinogen alpha, cystatin A, sAA (western blot analysis) and salivary cortisol were recorded for both smokers $(n=5)$ and nonsmokers $(n=4)$ after both smoking sessions (cigarette smoking/sham smoking). SAS PROC MIXED (SAS 9.4, SAS Institute, Cary, NC, USA) was used to fit repeated measures linear models to compare protein levels between smokers and non-smokers. Models were fit using either smoking status alone or smoking status and one additional covariate (baseline age or weight). More complicated multivariable models were not used because of the small number of observations. Each protein difference was modeled separately, and all tests were performed at $a=0.05$ level. Additional analysis was performed to observe any association between the protein ratios in smokers and non-smokers after smoking (or sham smoking) 
Cig 1 and Cig 2 using Spearman's correlation $\left(\mathrm{r}_{\mathrm{s}}\right)$. A previous proteomic profile of smokers using 5 subjects per group found significant differential expression of proteins, and was used for the sample size determination of the current study ${ }^{28}$.

\section{RESULTS}

\section{ITRAQ analysis}

A total of 484 proteins were identified in the pooled saliva samples by iTRAQ analysis (Supplementary file Table S1). The NCBI curated RefSeq protein sequence database, against which observed MS/MS spectra were searched by ProteinPilot (AB SCIEX, Framingham, MA), lists only one protein sequence per protein (to avoid duplicate entries). Thus, when a preproprotein version of secreted proteins is known, that is the single full-length sequence that is listed in the curated RefSeq protein sequence database, then many confident protein IDs are listed by name as the 'preproprotein' version of the sequence. However, manual inspection of the actual peptide sequences confidently identified shows that all of the peptides which were confidently identified and assigned to these full 'preprotein' sequences corresponded to peptides from the normally cleaved mature form of the identified proteins. With no peptides identified from the $\mathrm{N}$-terminal cleaved pre-protein segments, the peptides which were identified are therefore consistent with assignment of the protein ID corresponding to the peptides identified as being the mature secreted forms of the proteins.

\section{Characteristics of proteins identified in ITRAQ from saliva of smokers and non-smokers after smoking or sham smoking}

A heat map for subset of significant proteins depicts the differential expression of salivary proteins that were altered after smoking or sham smoking Cig 1 and Cig 2 in smokers and non-smokers (Figure 1a). Out of these, 24 proteins were significantly $(p<0.05)$ altered in smokers and non-smokers after smoking Cig 1 and sham smoking, respectively (Table 1) and only six proteins were commonly altered among these (Figure 1b). After smoking/sham smoking Cig 2, a total of 18 and 19 proteins were significantly altered in smokers and non-smokers, respectively (Table 1) and only two proteins were common among these (Figure 1c). The 8 common proteins were changing most likely because of smoking a cigarette rather than an act of smoking a cigarette and this needs to be verified in the future (Figure $1 b$ and $1 c$ ).

Table 1 describes the ratios of differentially expressed proteins identified in smokers and nonsmokers after smoking and sham smoking cigarettes, respectively. Several of these proteins were increased in smokers after smoking Cig 1 and Cig 2. To observe similarities in protein fold changes before and after Cig 1 and Cig 2 in smokers and non-smokers, a Spearman's correlation was also performed. Data analysis on 60 proteins from smokers showed $\mathrm{r}_{\mathrm{s}}=0.62369, \mathrm{p}(2$-tailed $)=1.019 \times 10^{-7}$, and from nonsmokers showed $r_{s}=0.03221, p(2$-tailed $)=0.80697$.

\section{Figure 1. a) Heat map for differential salivary} proteomics in smokers and non-smokers following smoking/sham smoking Cig 1 and Cig 2. b) List of common proteins expressed in saliva of smokers vs non-smokers after smoking/sham smoking Cig 1. c) List of common proteins expressed in saliva of smokers vs non-smokers after smoking/sham smoking Cig 2

a. a. UniProt ID A1AT_HUMAN A2ML1_HUMAN ACBP HUMAN ALDOA_HUMAN AMY1_HUMAN APOA-1_HUMAN APOA2_HUMAN APOA4_HUMAN B2MG_HUMAN BPIA2_HUMAN BPIB1_HUMAN CATD_HUMAN CUTA_HUMAN CYTA_HUMAN DAG1 HUMAN DAG1_HUMAN DMBT1_HUMAN DSG1_HUMAN EST1_HUMAN EZRI_HUMAN FCGBP_HUMAN FIBA HUMAN GRP78_HUMAN GSTO1_HUMAN HBA_HUMAN IL36G_HUMAN K1C13_HUMAN K1C14_HUMAN K1C16 HUMAN K22O_HUMAN MUC5B_HUMAN NGAL_HUMAN NQO1_HUMAN PRDX _ HUMAN PRTN3 HUMAN PTGR1_HUMAN
QSOX1_HUMAN QSOX1_HUMAN S10A7_HUMAN SAP_HUMAN STAT_HUMAN TCO1_HUMAN TGM3_HUMAN TPM3_HUMAN TRFE_HUMAN TRFL_HUMAN VAT1_HUMAN

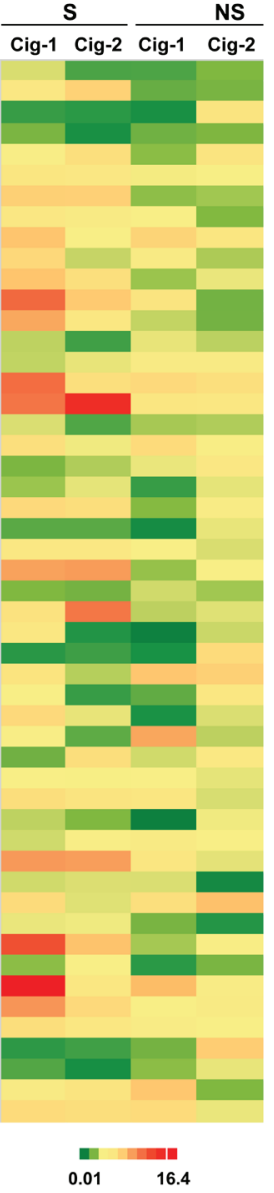

b.

\begin{tabular}{|c|c|c|}
\hline \multicolumn{3}{|c|}{$\begin{array}{l}\text { Common proteins in smokers and } \\
\text { non-smokers after smoking/sham- } \\
\text { smoking Cig } 1 .\end{array}$} \\
\hline & $\begin{array}{c}\text { Smokers } \\
\text { (S) }\end{array}$ & $\begin{array}{l}\text { Non-smokers } \\
\text { (NS) }\end{array}$ \\
\hline $\begin{array}{l}\text { UniProt ID } \\
\text { A2ML1_HUMAN } \\
\text { AMY1_HUMAN } \\
\text { APOA } 1 \text { HUUMAN } \\
\text { B2MG_HUMAN } \\
\text { EST1_HUMAN } \\
\text { VAT1_HUMAN }\end{array}$ & $\begin{array}{l}1.42 \\
1.56 \\
3.60 \\
2.25 \\
0.63 \\
2.03\end{array}$ & $\begin{array}{l}0.42 \\
0.98 \\
0.57 \\
1.29 \\
0.25 \\
2.00\end{array}$ \\
\hline $\begin{array}{l}\text { Mean ITRAQ } \\
\text { ratio }\end{array}$ & 1.92 & 0.92 \\
\hline
\end{tabular}

c.

Common proteins in smokers and non-smokers after smoking/shamsmoking Cig 2.

$\begin{array}{lcc}\begin{array}{c}\text { Smokers } \\ \text { (S) }\end{array} & \begin{array}{c}\text { Non-smokers } \\ \text { (NS) }\end{array} \\ \begin{array}{l}\text { UniProt ID } \\ \text { TPBU_HUMAN }\end{array} & 0.14 & 0.51 \\ \text { TPM_HUMAN } & 0.28 & 2.99 \\ \begin{array}{l}\text { Mean ITRAQ } \\ \text { ratio }\end{array} & \mathbf{0 . 2 1} & \mathbf{1 . 7 5} \\ & & \end{array}$


Table 1. List of proteins significantly altered in saliva of smokers or non-smokers after smoking and sham smoking, respectively, following iTRAQ analysis. The ratios of after/before in smokers and non-smokers are depicted along with the p-values and number of peptides for Cig 1 and Cig 2 . P-Values were also significant based on $q$ values $(+q<0.05 ;++q<0.001)$. Proteins highlighted in grey are higher in smokers after smoking Cig 1 and Cig 2 compared to that in non-smokers after sham smoking Cig 1 and Cig 2

\begin{tabular}{|c|c|c|c|c|c|c|c|c|c|c|c|c|}
\hline $\begin{array}{l}\text { UniProt ID } \\
\text { (HUMAN) }\end{array}$ & Name of protein & Peptides & $\begin{array}{l}\text { ACig 1/ } \\
\text { BCigl }\end{array}$ & $\begin{array}{c}\operatorname{Cig} I \mathrm{~S} \\
p\end{array}$ & $\begin{array}{l}\text { ACig2/ } \\
\text { BCig2 }\end{array}$ & $\begin{array}{c}\operatorname{Cig} 2 \mathrm{~S} \\
p\end{array}$ & $\begin{array}{l}\text { AShCigl/ } \\
\text { BShCigl }\end{array}$ & $\begin{array}{c}\text { Cig } 1 \text { NS } \\
p\end{array}$ & $\begin{array}{l}\text { AShCig2/ } \\
\text { BShCig2 }\end{array}$ & $\begin{array}{c}\text { Cig } 2 \text { NS } \\
p\end{array}$ & $\begin{array}{l}\text { Reported } \\
\text { in } \\
\text { smokers }\end{array}$ & References \\
\hline A1AT & Alpha-1-antitrypsin precursor & 12 & 0.86 & 0.790 & 0.31 & 0.084 & 0.33 & 0.045 & 0.52 & 0.080 & Yes & 24 \\
\hline A2ML1 & $\begin{array}{l}\text { Alpha-2-macroglobulin-like protein } 1 \\
\text { precursor }\end{array}$ & 61 & 1.42 & 0.041 & 2.65 & 0.016 & 0.42 & 0.021 & 0.49 & 0.077 & No & \\
\hline ACBP & Acyl-CoA-binding protein isoform 5 & 9 & 0.25 & 0.004 & 0.21 & 0.005 & 0.13 & 0.194 & 1.66 & 0.795 & No & \\
\hline ALBU & Serum albumin preproprotein & 228 & 0.50 & 0.092 & 0.14 & $0.001^{+}$ & 0.46 & 0.004 & 0.51 & 0.011 & Yes & 24 \\
\hline AMY1 & Alpha-amylase 1 precursor & 1724 & 1.55 & 0.003 & 1.38 & 0.002 & 0.98 & 0.005 & 1.00 & 0.840 & Yes & 24 \\
\hline ANXA6 & Annexin A6 isoform 1 & 3 & 0.49 & 0.393 & 3.80 & 0.204 & 24.43 & 0.033 & 0.47 & 0.322 & No & \\
\hline APOA1 & Apolipoprotein A-I preproprotein & 13 & 2.88 & 0.817 & 2.75 & 0.875 & 0.57 & 0.008 & 0.65 & 0.008 & Yes & 34 \\
\hline APOA2 & Apolipoprotein A-II preproprotein & 2 & 1.45 & 0.047 & 1.22 & 0.053 & 1.02 & 0.752 & 0.52 & 0.244 & Yes & 35 \\
\hline APOA4 & Apolipoprotein A-IV precursor & 4 & 3.60 & 0.006 & 1.05 & 0.011 & 2.51 & 0.006 & 1.58 & 0.277 & Yes & 19 \\
\hline B2MG & Beta-2-microglobulin precursor & 5 & 2.25 & 0.003 & 0.79 & 0.129 & 1.29 & 0.004 & 0.69 & 0.107 & Yes & 36 \\
\hline BPIB1 & $\begin{array}{l}\text { BPI fold-containing family B member } 1 \\
\text { precursor }\end{array}$ & 19 & 9.55 & 0.026 & 3.25 & 0.347 & 1.64 & 0.575 & 0.47 & 0.333 & Yes & 24 \\
\hline $\mathrm{CAH} 1$ & Carbonic anhydrase 1 & 3 & 20.32 & 0.033 & 1.37 & 0.823 & 0.07 & 0.094 & 0.77 & 0.497 & Yes & 37 \\
\hline $\mathrm{CAH} 6$ & Carbonic anhydrase 6 isoform 1 precursor & 117 & 5.30 & 0.014 & 1.53 & 0.182 & 0.77 & 0.912 & 0.47 & 0.020 & Yes & 24 \\
\hline CATD & Cathepsin D preproprotein & 12 & 0.76 & 0.865 & 0.28 & 0.003 & 0.92 & 0.915 & 0.74 & 0.631 & Yes & 38 \\
\hline CATF & Cathepsin F precursor & 1 & 1.82 & 0.366 & 1.38 & 0.552 & 1.19 & 0.722 & 87.90 & 0.019 & No & \\
\hline COPG2 & Coatomer subunit gamma-2 & 1 & 0.48 & 0.314 & 0.27 & 0.184 & 0.01 & 0.063 & 87.90 & 0.017 & No & \\
\hline COTL1 & Coactosin-like protein & 3 & 0.77 & 0.338 & 0.92 & 0.006 & 1.25 & 0.272 & 1.24 & 0.314 & Yes & 24 \\
\hline CRYAA & Alpha-crystallin A chain & 3 & 69.18 & 0.019 & 3.53 & 0.190 & 0.19 & 0.147 & 2.88 & 0.027 & Yes & 39 \\
\hline CUTA & Protein CutA isoform 1 & 3 & 9.20 & 0.213 & 1.82 & 0.421 & 2.13 & 0.413 & 1.92 & 0.045 & No & \\
\hline \multirow[t]{2}{*}{ CYTA } & Cystatin-A & 13 & 8.63 & 0.004 & 13.93 & 0.002 & 1.57 & 0.066 & 1.51 & 0.912 & Yes & 24 \\
\hline & & & & & & & & & & & & Contin \\
\hline
\end{tabular}




\section{Research Paper}

Table 1. Continued

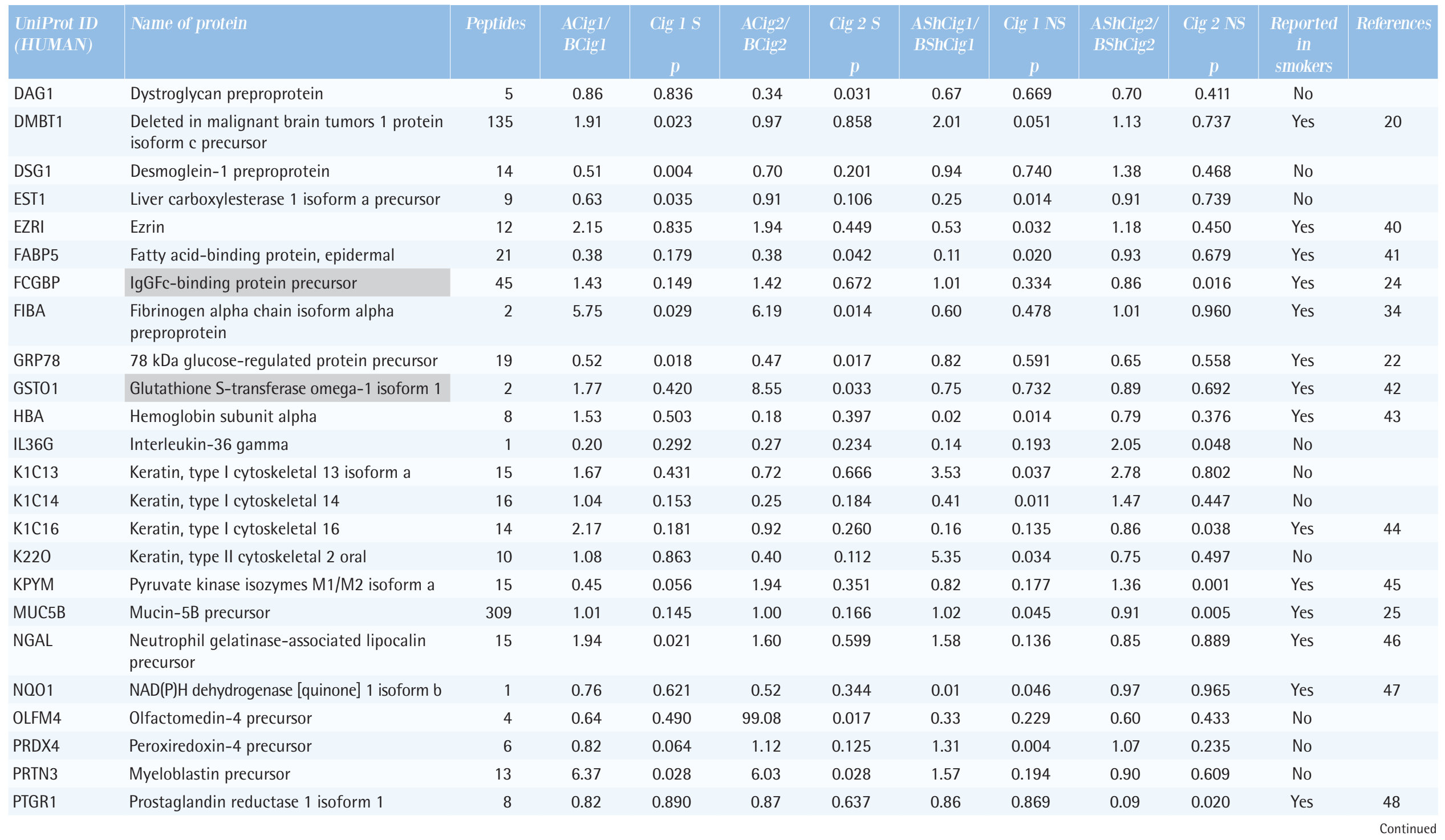




\section{Research Paper}

Table 1. Continued

\begin{tabular}{|c|c|c|c|c|c|c|c|c|c|c|c|c|}
\hline $\begin{array}{l}\text { UniProt ID } \\
\text { (HUMAN) }\end{array}$ & Name of protein & Peptides & $\begin{array}{l}\text { ACig 1/ } \\
\text { BCig I }\end{array}$ & $\begin{array}{c}\operatorname{Cig} 1 \mathrm{~S} \\
p\end{array}$ & $\begin{array}{l}\text { ACig2/ } \\
\text { BCig2 }\end{array}$ & $\begin{array}{c}\operatorname{Cig} 2 \mathrm{~S} \\
p\end{array}$ & $\begin{array}{l}\text { AShCigl/ } \\
\text { BShCigl }\end{array}$ & $\begin{array}{c}\text { Cig } 1 \text { NS } \\
p\end{array}$ & $\begin{array}{l}\text { AShCig2/ } \\
\text { BShCig2 }\end{array}$ & $\begin{array}{c}\text { Cig } 2 \text { NS } \\
p\end{array}$ & $\begin{array}{c}\text { Reported } \\
\text { in } \\
\text { smokers }\end{array}$ & References \\
\hline 0SOX1 & Sulfhydryl oxidase 1 isoform a precursor & 4 & 2.09 & 0.724 & 0.89 & 0.236 & 1.80 & 0.094 & 3.77 & 0.028 & No & \\
\hline RAB5C & RAS-related protein Rab-5C isoform $b$ & 1 & 1.06 & 0.891 & 0.65 & 0.482 & 2.31 & 0.276 & 80.91 & 0.020 & No & \\
\hline S10A7 & Protein S100-A7 & 22 & 0.94 & 0.099 & 0.96 & 0.361 & 0.49 & 0.026 & 0.18 & 0.003 & No & \\
\hline SAP & Prosaposin isoform a preproprotein & 10 & 11.38 & 0.022 & 3.70 & 0.179 & 0.66 & 0.758 & 1.13 & 0.812 & No & \\
\hline SODE & $\begin{array}{l}\text { Extracellular superoxide dismutase }[\mathrm{Cu}-\mathrm{Zn}] \\
\text { precursor }\end{array}$ & 1 & 2.11 & 0.306 & 3.34 & 0.198 & 0.36 & 0.232 & 46.13 & 0.020 & Yes & 21 \\
\hline SPB3 & Serpin B3 & 29 & 0.56 & 0.633 & 1.05 & 0.096 & 0.22 & 0.004 & 0.50 & 0.064 & Yes & 23 \\
\hline STAT & Statherin isoform a precursor & 133 & 16.44 & 0.002 & 1.51 & 0.409 & 3.94 & 0.084 & 1.17 & 0.442 & No & \\
\hline TC01 & Transcobalamin-1 precursor & 20 & 6.61 & 0.029 & 2.17 & 0.135 & 1.05 & 0.845 & 1.22 & 0.219 & Yes & 49 \\
\hline TGM3 & $\begin{array}{l}\text { Protein-glutamine gamma- } \\
\text { glutamyltransferase } \mathrm{E}\end{array}$ & 19 & 1.98 & 0.007 & 1.53 & 0.825 & 1.16 & 0.481 & 1.07 & 0.531 & No & \\
\hline TPM3 & Tropomyosin alpha-3 chain isoform 2 & 5 & 0.22 & 0.065 & 0.28 & 0.021 & 0.47 & 0.047 & 2.99 & 0.026 & No & \\
\hline TRFL & Lactotransferrin isoform 1 preprotein & 115 & 1.33 & 0.254 & 1.63 & 0.240 & 3.40 & 0.024 & 0.52 & 0.650 & SHS & 50 \\
\hline VAT1 & $\begin{array}{l}\text { Synaptic vesicle membrane protein VAT-1 } \\
\text { homolog }\end{array}$ & 5 & 2.03 & 0.003 & 1.96 & 0.003 & 2.00 & 0.003 & 0.94 & 0.731 & Yes & 24 \\
\hline ZG16B & $\begin{array}{l}\text { Zymogen granule protein } 16 \text { homolog B } \\
\text { precursor }\end{array}$ & 63 & 19.95 & 0.081 & 23.12 & 0.107 & 2.00 & 0.011 & 0.81 & 0.072 & Yes & 51 \\
\hline
\end{tabular}

Cig: cigarette. ACig: after smoking Cig. BCig: before smoking Cig. AShCig: after sham smoking Cig. BShCig: before sham smoking Cig. Cig 1: Cigarette-1. Cig 2: Cigarette-2. S: smokers. NS: non-smokers. SHS: secondhand smoke. 


\section{Validating iTRA0 data}

For validating iTRAQ data, initially, from the list of proteins that showed a high fold-change, were found to be significant (ProteinPilot p-value) in both smoking sessions for smokers (Table 1). Next, we selected proteins fibrinogen alpha and cystatin A for which ELISA kits were available and also included a protein ( $\mathrm{sAA}$ ) that was in fact a priori hypothesized protein associated with stress response based on a review of the literature as well as it had the maximum peptide hits for protein identification. In iTRAQ analysis, fibrinogen alpha was significantly elevated 5.8 -fold and 6.2-fold $(\mathrm{p}<0.05, \mathrm{q}>0.05)$ in smokers after smoking Gig 1 and Cig 2, respectively. In non-smokers, however, it was reduced 0.6-fold and unchanged $(\mathrm{p}>0.05, \mathrm{q}>0.05)$ after sham smoking Cig 1 and Cig 2, respectively (Figure 2a). Levels of fibrinogen alpha measured in individual saliva samples by Commercial ELISA revealed a 0.8-fold reduction and 1.2-fold increase ( $p>0.05)$ in fibrinogen levels in smokers after smoking Cig 1 and Cig 2, respectively. While in non-smokers fibrinogen levels were nonsignificantly elevated 1.1-fold and 1.58-fold after sham smoking Cig 1 and Cig 2, respectively (Figure $2 b)$. Interestingly, when smoking status and weight of participants were considered in a statistical model, the fibrinogen alpha levels measured by ELISA were significantly different $(p<0.05)$ among smokers and non-smokers after both smoking sessions (Supplementary file Table S2).

In iTRAQ analysis of pooled samples, cystatin A level was significantly increased 8.6-fold and 13.9fold $(p<0.005, q>0.05)$ in smokers after smoking Cig 1 and Cig 2, respectively, and in non-smokers it was elevated 1.5-fold ( $>>0.05, \mathrm{q}>0.05)$ after sham smoking Cig 1 and Cig 2 (Figure 2c). Upon analyzing the individual smoker and non-smoker saliva samples by Commercial ELISA kit, cystatin A levels were increased 1.65-fold ( $p>0.05)$ in non-smokers after sham smoking Cig 2, while in smokers no significant changes were observed (Figure 2d). The fold changes in ITRAQ analysis could not be validated in ELISA and one of the reasons for this difference may be pooling the samples for the former method. Additionally, when smoking status and age or weight of participants were considered in a statistical model, the cystatin A levels

Figure 2. Salivary fibrinogen alpha and cystatin A levels following iTRAQ analysis and validation by ELISA in smokers vs non-smokers. Fold change indicates ratio of protein levels after/before smoking/sham smoking in smokers and non-smokers, respectively. a) fibrinogen alpha levels from iTRAQ analysis. b) fibrinogen alpha levels by ELISA. c) cystatin A levels from iTRAQ analysis. d) cystatin A levels by ELISA

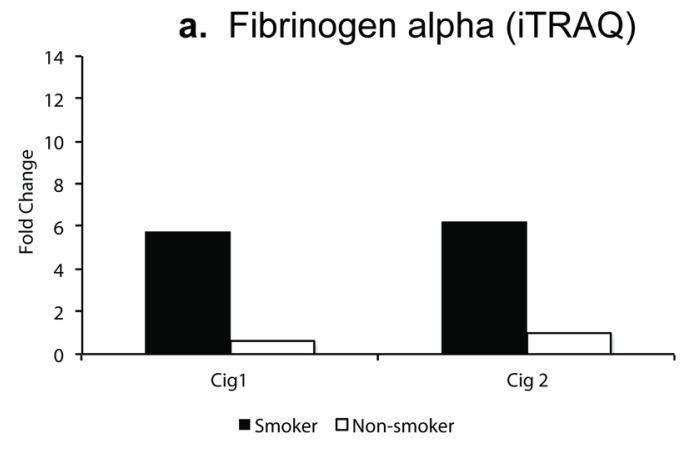

b. Fibrinogen alpha (ELISA)

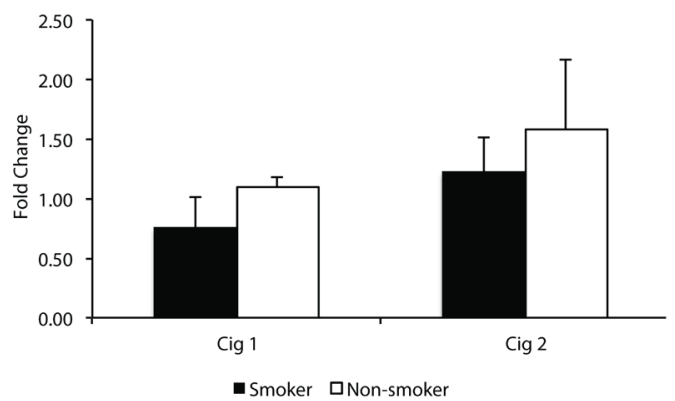

c. Cystatin A (iTRAQ)

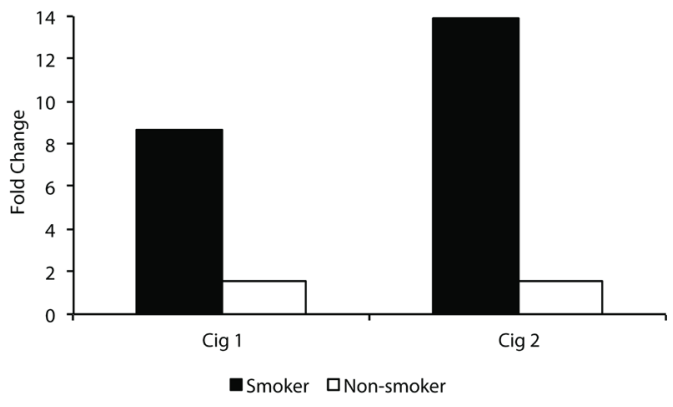

d. Cystatin A (ELISA)

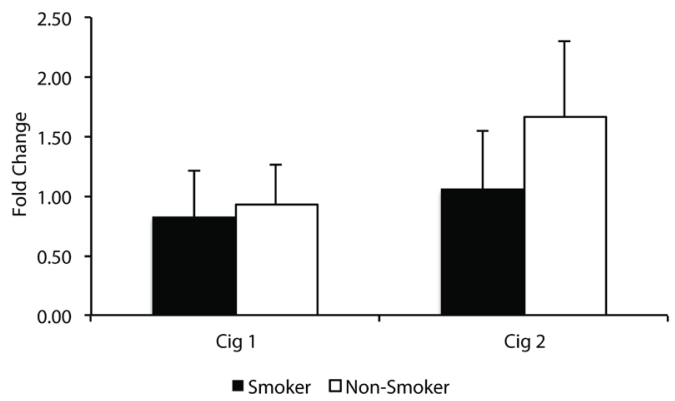


measured by ELISA were not statistically different ( $p>0.05)$ among smokers and non-smokers after both smoking sessions (Supplementary file Table S2).

sAA was significantly elevated after smoking Cig 1 and Cig 2 in smokers by 1.6 -fold and 1.4-fold $(p<0.005, q>0.05)$, respectively, as determined by iTRAQ data analysis (Figure 3a, Table 1). However, in non-smokers, sAA did not change after sham smoking Cig 1 and Cig 2.

Since sAA has been reported to be a marker for stress we wanted to examine if there were any modifications in SAA in the saliva. The ITRAQ analysis was based on pooled samples so we additionally examined individual saliva specimens by western blotting. Figure $3 \mathrm{~b}$ depicts the quantitative data as a ratio of 'after/before' smoking Cig 1 and Cig 2 in smokers as well as 'after/before' sham smoking Cig 1 and Cig 2 in non-smokers. $\beta$-actin was used to normalize the data presented in fold change of sAA in smokers versus non-smokers. Figure $3 c$ shows the sAA bands reacting with anti-sAA antibody in western blot analysis. Overall, baseline sAA protein bands showed higher intensity in non-smokers compared to smokers but the fold change after smoking was greater in smokers than non-smokers, yet not significant. An additional band running just above sAA likely being the glycosylated form of sAA was also expressed at higher intensity in non-smokers compared to smokers. When smoking status and age or weight of participants were considered in a statistical model, sAA levels measured by western blot showed a trend but were not statistically different $(\mathrm{p}=0.085)$ among smokers and non-smokers after both the smoking sessions (Supplementary file Table S2).

\section{Impact of smoking/sham-smoking on salivary cortisol}

The salivary cortisol levels were increased after smoking as well as sham smoking Cig 2 in smokers and non-smokers, respectively; however, there was a decrease in cortisol after Cig 1 in smokers as well as in non-smokers (Table 2). When smoking status and age or weight of participants were considered in a statistical model, the salivary cortisol levels were

Figure 3. Salivary alpha amylase (SAA) relative levels in smokers and non-smokers. a) SAA levels following iTRAQ analysis. b) SAA levels measured by western blot analysis. The sAA bands were normalized with corresponding $\beta$-actin levels for each sample. $c$ ) western blots for sAA in smokers and non-smokers. Fold changes in a) and b) indicate ratios of SAA levels after/before smoking/sham smoking in smokers and non-smokers, respectively. $B$ before and $A$ after smoking (or sham smoking in non-smokers). $N=5$ (smokers), $N=4$ (non-smokers).

a.

SAA

iTRAQ analysis

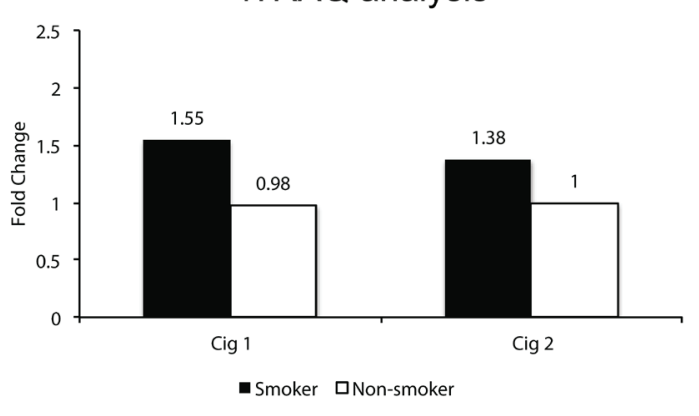

c.

Smokers b.

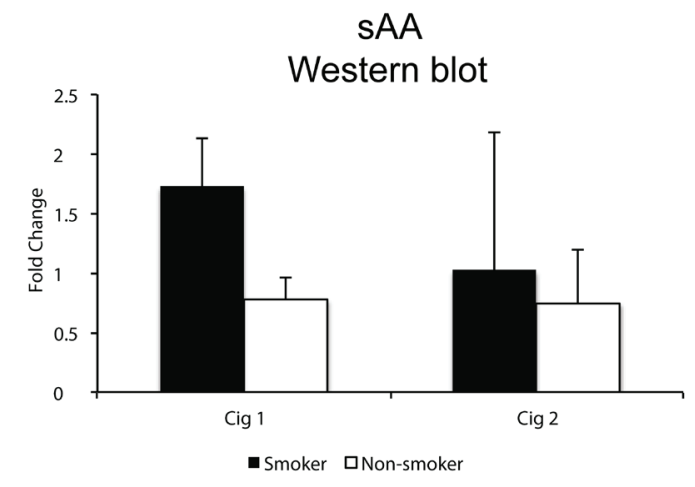

Non-smokers

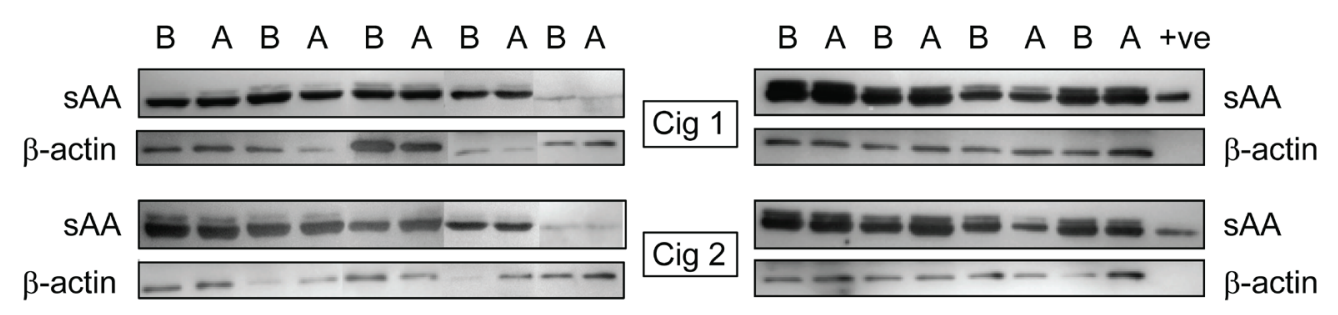


Table 2. Comparative SAA enzyme activity and cortisol levels in saliva of smokers and non-smokers before and after smoking/sham smoking Cig 1 and Cig 2

\begin{tabular}{|c|c|c|c|c|}
\hline Enzyme activity & $\begin{array}{c}\text { Before Cig } 1 \\
\text { Mean } \pm \text { SE }\end{array}$ & $\begin{array}{l}\text { After Cig I } \\
\text { Mean } \pm \text { SE }\end{array}$ & $\begin{array}{c}\text { Before Cig } 2 \\
\text { Mean } \pm \mathrm{SE}\end{array}$ & $\begin{array}{l}\text { After Cig } 2 \\
\text { Mean } \pm \text { SE }\end{array}$ \\
\hline Smokers sAA enzyme activity $(\mathrm{U} / \mathrm{mL})$ & $35.75 \pm 11.83$ & $33.59 \pm 11.26$ & $32.14 \pm 10.95$ & $33.85 \pm 10.42$ \\
\hline Non-smokers sAA enzyme activity $(\mathrm{U} / \mathrm{mL})$ & $59.45 \pm 15.20$ & $62.73 \pm 18.52$ & $61.91 \pm 14.33$ & $71.50 \pm 22.0$ \\
\hline Smokers Cortisol ( $\mu \mathrm{g} / \mathrm{dL})$ & $0.13 \pm 0.03$ & $0.10 \pm 0.03$ & $0.08 \pm 0.03$ & $0.10 \pm 0.03$ \\
\hline Non-smokers Cortisol ( $\mu \mathrm{g} / \mathrm{dL})$ & $0.20 \pm 0.02$ & $0.17 \pm 0.01$ & $0.14 \pm 0.01$ & $0.15 \pm 0.02$ \\
\hline
\end{tabular}

not statistically different ( $\mathrm{p}>0.05)$ among smokers and non-smokers after both smoking sessions (Supplementary file Table S2).

\section{DISCUSSION}

This study sought to determine the feasibility of using proteomics in human subjects' research to identify new protein markers in the saliva that change in response to an acute smoking event versus acute sham smoking event in smokers and non-smokers, respectively. Utilizing iTRAQ methodology we were able to identify proteins that might assist in understanding changes that occur in the stress response to smoking. This new information might assist in improving methods for behavioral and pharmacological interventions for smokers. A total of 484 salivary proteins were identified by iTRAQ method in our pilot study as being affected by cigarette smoking. Some of these proteins were reported for the first time in saliva of smokers.

Some of the proteins identified in the saliva of smokers after smoking a cigarette in our study have previously been reported in biomarker studies of smokers ${ }^{19-25,33-51}$ and several new proteins were reported for the first time in saliva of smokers in our analysis.

Furthermore, protein profiling revealed that the common proteins amongst smokers increased about 2 -fold on average (Figure 1b), while these were unchanged in non-smokers, indicating that after Cig 1 these protein changes were indeed impacted by smoking. Based on the proteins identified in our pilot study, we can begin to categorize proteins that change as a result of smoking and that have a role in nicotine dependence in smokers: AMY1, CAH1, CAH6, BPIA2, BPIB1, TCO1, NGAL, GSTO1 A2ML1, TGM3, and SAP are potential candidate proteins that are recommended to validate in a larger smoker study.

Several studies have shown that psychosocial and physical stressors can rapidly increase the sAA activity. Our study showed changes in sAA within 30 min of smoking a cigarette. In fact, sAA has been proposed as a potential non-invasive biomarker for $\mathrm{SNS}^{52}$. Salivary amylase along with glutathione S-transferase, and prolactin-induced protein have been shown to correlate with psychosocial stress ${ }^{4}$. In another study, acute stress increased salivary amylase and cystatins in medical students exposed to clinical simulations ${ }^{5}$. Genetically, sAA is coded by AMY1 gene and its copy number is positively correlated with sAA protein expression in humans, and that sAA amount is also positively correlated with its activity ${ }^{53,54}$. About $40-50 \%$ of saliva is composed of $\mathrm{sAA}^{52}$ and the latter is a mixture of two isoenzymes as glycosylated and non-glycosylated that differ by just $4 \mathrm{kDa}$. However, it is still not clear if these two isoenzymes differ in their clinical roles. In our western blot analysis, we noted both glycosylated and non-glycosylated forms of sAA in saliva of non-smokers as well as smokers (Figure $3 c)$. In a future study we will investigate the role of glycosylated sAA in behavior of smokers.

sAA activity is conventionally measured in saliva samples for studies analyzing psychosocial stress but, examining sAA activity in smokers may pose a potential technical problem. The aldehydes in smoke diminish the sAA activity in saliva ${ }^{55}$, therefore it may be underestimating the sAA activity in saliva samples from smokers.

Among other proteins that exhibited a smokingresponse, GSTO1, GRP78, and APOA4 have been reported to be involved in psychological stress ${ }^{4}$, mood disorders ${ }^{56}$, and depression ${ }^{57}$, respectively.

Our study employed a novel arm of sham smoking in non-smokers. Interestingly, we found protein 
changes in this group. It may be the act of smoking rather than nicotine exposure is associated with an acute response to changes in stress. Future studies may need to consider control conditions such as these to further understand whether the proteomic response to smoking is due to smoking behaviors or to nicotine exposure.

\section{Strengths and limitations}

The iTRAQ analysis of smokers $(n=5)$ and nonsmokers $(n=4)$ in our pilot study identified numerous proteins in saliva for the first time. There were consistent changes in proteins in repeating the smoking as well as sham-smoking sessions in smokers and non-smokers, respectively. Evidently, there were important lessons learned while analyzing these samples. For an initial approach using iTRAQ, pooling of samples was opted to obtain changes in global proteomic profile but, when we investigated these changes in individual samples by ELISA, the overall fold-change for selected proteins was not similar as noted for cystatin A and was true for fibrinogen. In western blot analysis for sAA, however, the trend was similar as observed in iTRAQ for smokers after smoking Cig 1. It will be critical to label individual saliva samples with a unique tag in order to measure an appropriate quantitative change rather than pooling the samples from each group. By pooling the samples, the assessment of potential group differences was potentially weakened. In addition, it is imperative to validate the results of iTRAQ by one or more methods specifically, if samples have been pooled initially. Findings are not entirely in the direction we expected. For example, cortisol levels were higher in non-smokers compared to smokers in this study although the literature also is inconsistent in this area. However, preliminary findings from our small study, with interesting behavior-related protein markers, could be replicated in a larger set of saliva samples from smokers and non-smokers in the future.

\section{CONCLUSIONS}

Our iTRAQ analysis identified several new proteins in saliva of smokers. Some of these novel proteins may respond to physiological or psychological stressors in smokers following smoking. However, further studies are needed to validate these findings and future experiments will require their validation in a larger sample size. Moreover, an understanding of combined expression for some of these proteins in addition to sAA and cortisol levels could potentially lead to new and improved methods for behavioral and pharmacological interventions. Candidate proteins that would be interesting to validate include: ACBP, A2ML1, APOA4, BPIB1, BPIA2, CAH1, CAH6, DSG1, EST1, GRP78, GSTO1, sAA, SAP, STAT, TCO1, and TGM3, in addition to cortisol.

\section{REFERENCES}

1. McCarthy M. Smoking remains leading cause of premature death in US. BMJ. 2014;348:g396. doi:10.1136/bmj.g396

2. Howes S, Hartmann-Boyce J, Livingstone-Banks J, Hong B, Lindson N. Antidepressants for smoking cessation. Cochrane Database Syst Rev. 2020;4(4):CD000031. doi:10.1002/14651858.CD000031.pub5

3. Parrott AC. Does cigarette smoking cause stress? Am Psychol. 1999;54(10):817-820. doi:10.1037//0003-066x.54.10.817

4. Trueba AF, Mizrachi D, Auchus RJ, Vogel PD, Ritz T. Effects of psychosocial stress on the pattern of salivary protein release. Physiol Behav. 2012;105(3):841-849. doi:10.1016/j.physbeh.2011.10.014

5. Marvin RK, Saepoo MB, Ye S, et al. Salivary protein changes in response to acute stress in medical residents performing advanced clinical simulations: a pilot proteomics study. Biomarkers. 2017;22(3-4):372-382. doi:10.1080/1354750X.2017.1279215

6. Gilbert DG, Meliska CJ, Williams CL, Jensen RA. Subjective correlates of cigarette-smoking-induced elevations of peripheral beta-endorphin and cortisol. Psychopharmacology (Berl). 1992;106(2):275-281. doi:10.1007/BF02801984

7. Kirschbaum C, Wüst S, Strasburger CJ. 'Normal' cigarette smoking increases free cortisol in habitual smokers. Life Sci. 1992;50(6):435-442. doi:10.1016/0024-3205(92)90378-3

8. Ghura S, Gross R, Jordan-Sciutto K, et al. Bidirectional Associations among Nicotine and Tobacco Smoke, NeuroHIV, and Antiretroviral Therapy. J Neuroimmune Pharmacol. 2020;15(4):694-714. doi:10.1007/s11481-019-09897-4

9. Li MD, Wang J. Neuroproteomics and its applications in research on nicotine and other drugs of abuse. Proteomics Clin Appl. 2007;1(11):1406-1427. doi:10.1002/prca.200700321

10. Billing AM, Revets D, Hoffmann C, Turner JD, Vernocchi $\mathrm{S}$, Muller CP. Proteomic profiling of rapid non-genomic and concomitant genomic effects of acute restraint stress on rat thymocytes. J Proteomics. 2012;75(7):2064-2079. doi:10.1016/j.jprot.2012.01.008

11. Hwang YY, Li MD. Proteins differentially expressed in response to nicotine in five rat brain regions: identification 
using a 2-DE/MS-based proteomics approach. Proteomics. 2006;6(10):3138-3153. doi:10.1002/pmic.200500745

12. Cecconi D, Tessari M, Willé DR, et al. Serum proteomic analysis during nicotine self-administration, extinction and relapse in rats. Electrophoresis. 2008;29(7):15251533. doi:10.1002/elps.200700388

13. Guingab-Cagmat J, Bauzo RM, Bruijnzeel AW, Wang KK, Gold MS, Kobeissy FH. Methods in tobacco abuse: proteomic changes following second-hand smoke exposure. Methods Mol Biol. 2012;829:329-48. doi: 10.1007/978-1-61779-458-2_22

14. Steptoe A, Ussher M. Smoking, cortisol and nicotine. Int J Psychophysiol. 2006;59(3):228-235. doi:10.1016/j.ijpsycho.2005.10.011

15. Choi D, Ota S, Watanuki S. Does cigarette smoking relieve stress? Evidence from the event-related potential (ERP). Int J Psychophysiol. 2015;98(3 Pt 1):470-476. doi:10.1016/j.ijpsycho.2015.10.005

16. Hajek P, Taylor T, McRobbie H. The effect of stopping smoking on perceived stress levels. Addiction. 2010;105(8):14661471. doi:10.1111/j.1360-0443.2010.02979.x

17. Rohleder N, Nater UM, Wolf JM, Ehlert U, Kirschbaum C. Psychosocial stress-induced activation of salivary alpha-amylase: an indicator of sympathetic activity? Ann N Y Acad Sci. 2004;1032:258-263. doi:10.1196/annals.1314.033

18. Bosch JA, Veerman EC, de Geus EJ, Proctor GB. a-Amylase as a reliable and convenient measure of sympathetic activity: don't start salivating just yet! Psychoneuroendocrinology. 2011;36(4):449-453. doi:10.1016/j.psyneuen.2010.12.019

19. Bortner JD Jr, Richie JP Jr, Das A, et al. Proteomic profiling of human plasma by iTRAQ reveals downregulation of ITI-HC3 and VDBP by cigarette smoking. J Proteome Res. 2011;10(3):1151-1159. doi:10.1021/pr100925p

20. Baraniuk JN, Casado B, Pannell LK, et al. Protein networks in induced sputum from smokers and COPD patients. Int J Chron Obstruct Pulmon Dis. 2015;10:19571975. doi:10.2147/COPD.S75978

21. Regan EA, Mazur W, Meoni E, et al. Smoking and COPD increase sputum levels of extracellular superoxide dismutase. Free Radic Biol Med. 2011;51(3):726-732. doi:10.1016/j.freeradbiomed.2011.05.008

22. Aksoy MO, Kim V, Cornwell WD, et al. Secretion of the endoplasmic reticulum stress protein, GRP78, into the BALF is increased in cigarette smokers. Respir Res. 2017;18(1):78. doi:10.1186/s12931-017-0561-6

23. Landi C, Bargagli E, Magi B, et al. Proteome analysis of bronchoalveolar lavage in pulmonary langerhans cell histiocytosis. J Clin Bioinforma. 2011;1:31. doi:10.1186/2043-9113-1-31

24. Jessie K, Pang WW, Haji Z, Rahim A, Hashim OH. Proteomic analysis of whole human saliva detects enhanced expression of interleukin-1 receptor antagonist, thioredoxin and lipocalin-1 in cigarette smokers compared to non-smokers. Int J Mol Sci. 2010;11(11):4488-4505. doi:10.3390/ijms11114488

25. Taniguchi M, Iizuka J, Murata Y, et al. Multimolecular salivary mucin complex is altered in saliva of cigarette smokers: detection of disulfide bridges by Raman spectroscopy. Biomed Res Int. 2013;2013:168765. doi:10.1155/2013/168765

26. Ma L, Muscat J, Sinha R, Sun D, Xiu G. Proteomics of exhaled breath condensate in lung cancer and controls using data-independent acquisition (DIA): a pilot study. J Breath Res. 2020. doi:10.1088/1752-7163/abd07e

27. van der Vaart H, Postma DS, Timens W, ten Hacken NH. Acute effects of cigarette smoke on inflammation and oxidative stress: a review. Thorax. 2004;59(8):713-721. doi:10.1136/thx.2003.012468

28. Franciosi L, Postma DS, van den Berge M, et al. Susceptibility to COPD: differential proteomic profiling after acute smoking. PLoS One. 2014;9(7):e102037. doi:10.1371/journal.pone.0102037

29. Krebs NM, Chen A, Zhu J, et al. Comparison of Puff Volume With Cigarettes per Day in Predicting Nicotine Uptake Among Daily Smokers. Am J Epidemiol. 2016;184(1):48-57. doi:10.1093/aje/kwv341

30. Sinha I, Karagoz K, Fogle RL, et al. 'Omics' of Selenium Biology: A Prospective Study of Plasma Proteome Network Before and After Selenized-Yeast Supplementation in Healthy Men. OMICS. 2016;20(4):202-213. doi:10.1089/omi.2015.0187

31. The R Foundation. The R Project for Statistical Computing. Accessed March 8, 2021. https://www.Rproject.org

32. Levine A, Zagoory-Sharon O, Feldman R, Lewis JG, Weller A. Measuring cortisol in human psychobiological studies. Physiol Behav. 2007;90(1):43-53. doi:10.1016/j. physbeh.2006.08.025

33. Hellhammer DH, Wüst S, Kudielka BM. Salivary cortisol as a biomarker in stress research. Psychoneuroendocrinology. 2009;34(2):163-171. doi:10.1016/j.psyneuen.2008.10.026

34. Sigurdsson G Jr, Gudnason V, Sigurdsson G, Humphries SE. Interaction between a polymorphism of the apo A-I promoter region and smoking determines plasma levels of HDL and apo A-I. Arterioscler Thromb. 1992;12(9):10171022. doi:10.1161/01.atv.12.9.1017

35. Mero N, Van Tol A, Scheek LM, et al. Decreased postprandial high density lipoprotein cholesterol and apolipoproteins $\mathrm{A}-\mathrm{I}$ and $\mathrm{E}$ in normolipidemic smoking men: relations with lipid transfer proteins and LCAT activities. J Lipid Res. 1998;39(7):1493-1502. Accessed March 8, 2021. https://www.jlr.org/action/ showPdf?pii=S0022-2275\%2820\%2932531-1

36. Laisalmi M, Kokki H, Soikkeli A, et al. Effects of cigarette smoking on serum fluoride concentrations and renal function integrity after 1 MAC-h sevoflurane 
anaesthesia. Acta Anaesthesiol Scand. 2006;50(8):982987. doi:10.1111/j.1399-6576.2006.01061.x

37. Taskin MI, Bilen C, Ergun A, Gencer N, Inceboz U. In vitro effects of estrogen and progesterone containing drugs on human erythrocyte carbonic anhydrase I and II isozymes in women smokers and nonsmokers. J Chin Med Assoc. 2015;78(9):513-519. doi:10.1016/j.jcma.2015.03.014

38. Gonçalves I, Hultman K, Dunér P, et al. High levels of cathepsin D and cystatin B are associated with increased risk of coronary events. Open Heart. 2016;3(1):e000353. doi:10.1136/openhrt-2015-000353

39. Chowdhury A, Choudhury A, Chakraborty S, et al. p-Benzoquinone-induced aggregation and perturbation of structure and chaperone function of a-crystallin is a causative factor of cigarette smokerelated cataractogenesis. Toxicology. 2018;394:11-18. doi:10.1016/j.tox.2017.11.018

40. Gao W, Zhang C, Feng Y, et al. Fascin-1, ezrin and paxillin contribute to the malignant progression and are predictors of clinical prognosis in laryngeal squamous cell carcinoma. PLoS One. 2012;7(11):e50710. doi:10.1371/journal.pone.0050710

41. Gally F, Chu HW, Bowler RP. Cigarette smoke decreases airway epithelial FABP5 expression and promotes Pseudomonas aeruginosa infection. PLoS One. 2013;8(1):e51784. doi:10.1371/journal.pone.0051784

42. Tung MC, Wang YH, Yeh SD, et al. Combined effects of GSTO1 and SULT1A1 polymorphisms and cigarette smoking on urothelial carcinoma risk in a Taiwanese population. J Formos Med Assoc. 2014;113(9):640-647. doi:10.1016/j.jfma.2012.08.015

43. Chen HC, Ip SW, Lin FD. Simultaneous Mass Spectrometric Analysis of Methylated and Ethylated Peptides in Human Hemoglobin: Correlation with Cigarette Smoking. Chem Res Toxicol. 2017;30(11):20742083. doi:10.1021/acs.chemrestox.7b00234

44. Lima CF, Leite SF, Carvalho YR, Cabral LA, Balducci I, Almeida JD. Cytokeratin profile in exfoliative cytology of smokers. Anal Quant Cytol Histol. 2011;33(1):19-24.

45. Demır AS, Erdenen F, Müderrısoğlu C, et al. Diagnostic and prognostic value of tumor M2-pyruvate kinase levels in patients with colorectal canhcer. Turk J Gastroenterol. 2013;24(1):36-42.

46. Wang Y, Jia M, Yan X, et al. Increased neutrophil gelatinase-associated lipocalin (NGAL) promotes airway remodelling in chronic obstructive pulmonary disease. Clin Sci (Lond). 2017;131(11):1147-1159. doi:10.1042/CS20170096

47. Kim JH, Hong YC. Interactive effect of smoking and NQO1 haplotypes on lung cancer risk. J Korean Med Sci. 2015;30(3):221-226. doi:10.3346/jkms.2015.30.3.221

48. Na HK, Kim M, Chang SS, et al. Tobacco smokingresponse genes in blood and buccal cells. Toxicol Lett. 2015;232(2):429-437. doi:10.1016/j.toxlet.2014.10.005

49. Piyathilake CJ, Macaluso M, Hine RJ, Vinter DW, Richards
EW, Krumdieck CL. Cigarette smoking, intracellular vitamin deficiency, and occurrence of micronuclei in epithelial cells of the buccal mucosa. Cancer Epidemiol Biomarkers Prev. 1995;4(7):751-758. Accessed March 8, 2021. https://cebp.aacrjournals.org/content/ cebp/4/7/751.full.pdf

50. Jenabian N, Pouramir M, Motallebnejad M, Bamdadian J, Rahimi-Rad M. Evaluation of the Effect of Passive Smoking on Lactoferrin and AST on 12 - 15 Years Old Children and Adolescents. Iran J Pediatr. 2015;25(5):e2996. doi:10.5812/ijp.2996

51. Heo SM, Lee S, Wang H, Jeong JH, Oh SW. Levels of common salivary protein 1 in healthy subjects and periodontal patients. J Periodontal Implant Sci. 2016;46(5):320-328. doi:10.5051/jpis.2016.46.5.320

52. Nater UM, Rohleder N. Salivary alpha-amylase as a noninvasive biomarker for the sympathetic nervous system: current state of research. Psychoneuroendocrinology. 2009;34(4):486-496. doi:10.1016/j.psyneuen.2009.01.014

53. Perry GH, Dominy NJ, Claw KG, et al. Diet and the evolution of human amylase gene copy number variation. Nat Genet. 2007;39(10):1256-1260. doi:10.1038/ng2123

54. Mandel AL, Peyrot des Gachons C, Plank KL, Alarcon $\mathrm{S}$, Breslin PA. Individual differences in AMY1 gene copy number, salivary a-amylase levels, and the perception of oral starch. PLoS One. 2010;5(10):e13352. doi:10.1371/journal.pone.0013352

55. Weiner D, Levy Y, Khankin EV, Reznick AZ. Inhibition of salivary amylase activity by cigarette smoke aldehydes. J Physiol Pharmacol. 2008;59 Suppl 6:727-737. Accessed March 8, 2021. http://www.jpp.krakow.pl/journal/ archive/12_08_s6/articles/72_article.html

56. Timberlake 2nd MA, Dwivedi Y. Altered Expression of Endoplasmic Reticulum Stress Associated Genes in Hippocampus of Learned Helpless Rats: Relevance to Depression Pathophysiology. Front Pharmacol. 2016;6:319. doi:10.3389/fphar.2015.00319

57. Ota VK, Chen ES, Ejchel TF, et al. APOA4 polymorphism as a risk factor for unfavorable lipid serum profile and depression: a cross-sectional study. J Investig Med. 2011;59(6):966-970. doi:10.2310/JIM.0b013e31822467cd

CONFLICTS OF INTEREST

The authors have each completed and submitted an ICMJE form for disclosure of potential conflicts of interest. The authors declare that they have no competing interests, financial or otherwise, related to the current work. J. Muscat reports that he received support from NIH.

\section{FUNDING}

This work was supported by the National Institute on Drug Abuse, National Institutes of Health (Proposal number R01DA026815) and partially by National Heart, Lung, and Blood Institute (Proposal number R01HL152436). 
ETHICAL APPROVAL AND INFORMED CONSENT

All the participants signed a consent form prior to their participation in the pilot study. The study was conducted in accordance with the Declaration of Helsinki, and the protocol was approved by the Institutional Review Board (IRB\# PRAMS042265EP) of Penn State University College of Medicine.

DATA AVAILABILITY

The data supporting this research can be found in the Supplementary file.

\section{AUTHORS' CONTRIBUTIONS}

Research Concept and Design: JEM, JPR Jr and RS. Collection and/ or assembly of data: IS, JM, NMK and AES. Data analysis and interpretation: IS, VAW, JEM and RS. Writing manuscript: IS, JEM and RS. All authors read and approved the final manuscript.

PROVENANCE AND PEER REVIEW

Not commissioned; externally peer reviewed. 